\title{
Relationship between bioleaching performance, bacterial community structure and mineralogy in the bioleaching of a copper concentrate in stirred tank reactors
}

P. Spolaore $^{1 *}$, C. Joulian ${ }^{1}$, J. Gouin ${ }^{2}$, D. Morin ${ }^{1}$ and P. d'Hugues ${ }^{1}$

${ }^{1}$ BRGM, EPI/ECO, 3 Ave. C. Guillemin, 45060 Orléans cedex 2, France

${ }^{2}$ BRGM, REM/MESY, 3 Ave. C. Guillemin, 45060 Orléans cedex 2, France

*Corresponding author

Pauline Spolaore

Tel: +33(0)238644829

Fax: +33(0)238643680

E-mail address: p.spolaore@brgm.fr

\begin{abstract}
During the Bioshale European project, a techno-economic study of the bioleaching of a copper concentrate originating from a black shale ore was carried out. This concentrate is a multi-mineral resource in which the copper sulphides are mainly chalcocite, covellite, bornite and chalcopyrite. The experiments undertaken to produce the techno-economic data were also an opportunity to carry out more fundamental research. The objective of this work was to combine the results of the bioleaching experiments, in terms of copper recovery, with the results of bacterial community monitoring and mineralogy residue analysis.
\end{abstract}

Batch and continuous bioleaching tests were carried out with $10 \%$ solids, at $42{ }^{\circ} \mathrm{C}$ and with a pH between 1.2 and 1.6. Final copper recovery was higher in batch cultures than in continuous mode (>95\% vs. 91\%). Mineralogical analysis showed that the limiting factor for copper recovery was incomplete chalcopyrite dissolution in both cases. However, chalcopyrite was even less dissolved in continuous conditions. This was also related to a variation in bacterial community structure. The population in all tests was composed of Acidithiobacillus caldus, Leptospirillum ferriphilum and one or two species of Sulfobacillus (thermosulfidooxidans and sometimes benefaciens) but Sulfobacillus and more generally sulphur oxidizers were more represented in batch mode.

It was proposed that, due to their capacity to reduce inorganic compounds, sulphur oxidizers may be efficient in limiting chalcopyrite surface hindering. It may help to better dissolve this mineral and reach a better copper recovery.

Key words: bioleaching, black shale, copper, stirred-tank reactor, Sulfobacillus 


\section{Introduction}

Bioleaching has been studied for over 30 years and is nowadays a well established process. One way to perform bioleaching is the continuous stirred tank reactor technology (CSTR). It is a commercial reality for the treatment of refractory gold ore concentrates (Arrascue and van Niekerk 2006; van Aswegen et al 2007), but has also been used in one case for the treatment of a cobalt-rich pyrite concentrate (Morin and d'Hugues 2007). Bioleaching in CSTR represents an attractive alternative to conventional roasting or pressure oxidation techniques because it offers several advantages: operational simplicity, lower capital and operating costs, environment friendliness and suitability for the treatment of complex and low grade ores (Brierley and Brierley 2001; Watling 2006). In the current context, where mineral resources are becoming of lower grade and more complex, the latest advantage is of particular importance. However, to widen the possible applications of CSTR technology and to be as competitive as the other technologies, some research still needs to be undertaken.

The optimization of process operating parameters is a classical approach to improve CSTR process performances and has been carried out in many studies over the last 10 years. For example, d'Hugues et al (1997) studied the influence of agitation/aeration rates, nutrient medium composition, and carbon dioxide enrichment on the dissolution of cobalt from a pyrite concentrate. Gericke and Pinches (1999) reported the results of a 280 days plant operation treating a copper sulphide concentrate using hyperthermophilic bacteria. They modified the feed's solids concentration and the overall mean pulp residence time. Some more recent research dealt with zinc recovery from a concentrate treated in a $160 \mathrm{~L}$ 4-stage continuous bioreactor (Pani et al 2003), the bioleaching of a Cananea copper concentrate (López-Juárez and Rivera-Santillán 2005) and the use of silver as a chemical catalyst in chalcopyrite bioleaching (Cancho et al 2007).

In addition, it is also necessary to perform complementary fundamental research to understand leaching phenomena and to identify the important parameters influencing process performance. Molecular ecology as a means of monitoring bacterial community structure gives new insights into bioleaching processes. The techniques available to carry out molecular microbial ecology are varied and have been reviewed extensively (Johnson and Hallberg 2007; Shippers 2007). They 
comprise CE-SSCP (Foucher et al 2003), DGGE (Demergasso et al 2005; Halinen et al 2009), real-time quantitative PCR (Zhang et al 2009). Some authors also combined culture dependent (plating) and biomolecular approaches (T-RLFP) (Wakeman et al 2008).

Mineralogy also has an important role in the bioprocessing of ores and concentrates. In heap bioleaching, acid consumption by gangue minerals is a key parameter and may have a detrimental effect (Brierley 2001; Halinen et al 2009). The nature of the metal-rich mineral phase also has an influence on metal recovery. For example it is well known that for copper sulphides, chalcocite and bornite are easily bioleached while covellite and chalcopyrite are more difficult to solubilise. However, little quantitative research on the correlations between ore mineralogy, reaction chemistry and leach residue mineralogy has been reported (Watling 2006). Whittington and coworkers (2003a and b) placed a particular emphasis on the mineralogy of the residue in their study on pressure acid leaching of arid-region nickel laterite ore. Helle and Kelm (2005) also conducted several investigations on mineralogical changes during acid leaching of oxide copper ore. Marquez et al (2006) noted that an appropriate understanding of the mineralogy in the ore and its transformation is essential to design and operate any industrial system.

The aim of the Bioshale European project was to define an innovative biotechnological process for the eco-efficient exploitation of black shale ores for metal production (d'Hugues et al 2008; http://bioshale.brgm.fr/). The technical feasibility of bioleaching an organic rich copper flotation concentrate originating from a black shale ore deposit was demonstrated during this project. The economy of the process was also evaluated and shown to be competitive (Spolaore et al 2009). The experiment conducted to produce data for the economic study was combined with more fundamental research. This paper presents the combined results of leaching performance, molecular ecology monitoring and mineralogy residue analysis. This helps to improve understanding of the bioleaching of a multi-mineral resource. 


\section{Material and methods}

\subsection{Bioshale-BRGM bacterial consortium}

The culture originated from a mixture of two consortia cultured for many years on both a cobaltiferous pyrite and a copper concentrate. It was subcultured several times in batch mode on the copper concentrate before being used as an inoculum in this study.

\subsection{Copper concentrate}

The copper concentrate came from a black shale ore and was produced by a Polish concentrator. The main characteristics of the sample were as follows: $\mathrm{Cu} 16.1 \%$, $\mathrm{Ag} 840 \mathrm{mg} / \mathrm{kg}, \mathrm{Fe} 7.1 \%$, sulphur as sulphide $11.5 \%$, inorganic $\mathrm{C} 2.1 \%$ and organic C $8.2 \%$, particle size (cumulative passing 80\%) $40 \mu \mathrm{m}$. The copper sulphide composition of this material was determined by mineralogical analysis.

\subsection{Nutritive media}

The basic nutrient medium was the 0Km medium (Battaglia et al 1994). Its standard composition was the following: $\left(\mathrm{NH}_{4}\right)_{2} \mathrm{SO}_{4}, 3.70 \mathrm{~g} \mathrm{~L}^{-1} ; \mathrm{H}_{3} \mathrm{PO}_{4}, 0.80 \mathrm{~g} \mathrm{~L}^{-}$ ${ }^{1}$; $\mathrm{MgSO}_{4} .7 \mathrm{H}_{2} \mathrm{O}, 0.52 \mathrm{~g} \mathrm{~L}^{-1}$; $\mathrm{KOH}, 0.48 \mathrm{~g} \mathrm{~L}^{-1}$.

\subsection{Laboratory-scale batch tests}

Batch experiments with 10\% solids were carried out in 2 L laboratory-scale glass reactors thermostated at $42^{\circ} \mathrm{C}$. $\mathrm{pH}$ was maintained under 1.7 by addition of $\mathrm{H}_{2} \mathrm{SO}_{4}$ $\left(20 \% \mathrm{v} \mathrm{v}^{-1}\right)$ when necessary. Air $\left(120 \mathrm{~L} \mathrm{~h}^{-1}\right)$ enriched with $\mathrm{CO}_{2}(1 \%)$ was injected beneath a turbine (rotation speed at $400 \mathrm{rpm}$ ) at the bottom of the reactor via a stainless steel pipe. Five identical experiments were run to determine copper dissolution kinetics, copper recovery and their variability.

\subsection{Laboratory-scale continuous operation}

The continuous bioleaching operation was carried out in a laboratory-scale unit equipped with 3 stirred reactors, one of $50 \mathrm{~L}$ (R1) followed by two of $20 \mathrm{~L}$ operating capacity (R2, R3). The tanks were all made from 304-L stainless-steel and had a height/diameter ratio equal to 1 . The reactors were arranged in cascade so that the pulp passes from one tank to the next one by overflowing. Air enriched 
with $\mathrm{CO}_{2}(1 \%)$ was injected beneath the turbine at the bottom of the tank. The top of the reactors were connected to a condenser system to prevent excessive evaporation. The same mixing system (BROGIM ${ }^{\circledR}$ - BRGM/MRM) was mounted in all tanks on a rotating shaft.

The feed was made up of a high density pulp of concentrate flow $\left(30 \% \mathrm{wt} \mathrm{wt}^{-1}\right.$ in water) and a concentrated nutritive medium flow. The two feed flows were pumped separately into the first tank to obtain a $10 \%$ solids ratio for the feed pulp. Temperature was maintained constant at $42^{\circ} \mathrm{C}$ by circulating cold water through an internal stainless-steel coil for cooling and by an external electric ribbon for heating. In the first tank, the $\mathrm{pH}$ was regulated around 1.5 by adding $\mathrm{H}_{2} \mathrm{SO}_{4}(20 \%$ $\mathrm{v} \mathrm{v}^{-1}$ ) in the pulp. $\mathrm{pH}$ regulation was not necessary in the other tanks.

To start the continuous bioleaching operation, a batch culture was conducted in the first reactor of the unit $(\mathrm{R} 1,50 \mathrm{~L})$. The operating conditions were the same as the one applied for the lab-scale batch experiments. When the bacteria entered the exponential growth phase, continuous feed started.

\subsection{Analytical techniques}

For the batch and continuous experiments, redox potential and $\mathrm{pH}$ were measured directly in the pulp. Copper and total iron concentrations were measured by atomic absorption spectroscopy (Varian SpectrAA-300) in the supernatant fraction from $0.45 \mu \mathrm{m}$ filtered culture samples.

When the laboratory pilot-scale unit was operating at a steady state, samples were collected from the overflowing pulp at the exit of the reactors and from the initial pulp feed. Samples of pulp were first filtered with a Büchner funnel. The filtered solid material was then rinsed with a sulphuric acid solution at $\mathrm{pH} 1.5$ and dried. Copper, iron and other chemical elements contained in the solid and liquid phases were analysed by atomic absorption. The totality of the pulp obtained at the end of batch tests $(2 \mathrm{~L})$ was treated in the same way.

BILCO ${ }^{\circledR}$ software was used to analyse experimental data and obtain a process mass balance. The coherent data were then processed to estimate operating parameters and performances (copper dissolution rates, final copper recovery). 


\subsection{Bacterial community structure}

Bacterial community structure was monitored at the end of the batch experiments (lab-scale tests, start-up of the continuous operation and supplementary batch test in R4). It was also determined in the first two reactors of the bioleaching installation after 12 days of continuous operating.

\section{Genomic DNA extraction}

$0.5 \mathrm{~mL}$ of homogenous bioleaching pulp was centrifuged (10 min, $10000 \mathrm{~g})$ and the resulting pellet was washed twice by re-suspension in $100 \mathrm{mM}$ citrate (pH 4). DNA was extracted from the washed pellets with the FastDNA Spin Kit for Soil (Bio101) using a modified procedure that included a treatment with $5.5 \mathrm{M}$ guanidine thiocyanate recommended by the manufacturer for high organic matter content samples. A slight modification of the protocol was introduced: the mechanical lysing step was repeated twice for better cell disruption.

\section{CE-SSCP monitoring}

The V3 region (E. coli position 331 to 533) of 16S rRNA genes of members of the Bacteria domain was amplified $\left(25\right.$ cycles, hybridization at $\left.61^{\circ} \mathrm{C}\right)$ from DNA extracts with the universal reverse primer w34 (5'-

TTACCGCGGCTGCTGGCAC-3') and the eubacterial forward primer w49 (5'ACGGTCCAGACTCCTACGGG-3') 5' end-labelled with the fluorescent dye FAM. CE-SSCP analyses were performed on formamide and heat denaturated, 5to 200-fold diluted PCR products. Assignment of strain names was performed by comparison of peak migration position on the profile obtained for reactor samples with that of pure reference strains.

As bacterial population assessment is based on PCR, data produced can only be regarded as semi-quantitative and will preferably be used to compare populations.

\subsection{Mineralogical analysis}

In order to determine the different proportions of each mineral phase quantitatively, the following protocol was used. Bromoform (density 2.8) densimetric separation was performed to separate heavy minerals from barren minerals and organic matter. Then, the concentrate of heavy minerals was compacted at high pressure using an anvil and the "compact disk" resulting from 
the process was polished. Finally, a CAMECA SX50 electron probe microanalyser (EPMA) equipped with 5 spectrometers (WDS technique) was used to determine the proportions of each mineral phase in a similar way to the counting point technique.

\section{Results}

\subsection{Batch tests}

A non-oxidative pre-treatment $\left(170 \mathrm{~g} \mathrm{H}_{2} \mathrm{SO}_{4} \mathrm{~kg}^{-1}\right)$ of the concentrate was carried out before the bioleaching step. The objective was to neutralize most of the carbonates that may, by dissolution, cause a $\mathrm{pH}$ increase and as a consequence a bacterial inhibition. Only a negligible part (between 3 and 6\%) of the copper initially present in the solids and more than $90 \%$ of the inorganic carbon was solubilised by this treatment (data not shown). Figure 1 presents the copper dissolution kinetics in five identical batch tests. Final copper recovery reached between 95 and $97 \%$ in $150 \mathrm{~h}$ (6.25 days) and the maximal copper leaching rate was evaluated at $255+/-11 \mathrm{mg} \mathrm{L}^{-1} \mathrm{~h}^{-1}$. The $\mathrm{Cu}$-sulphides mineralogical analysis was performed on the concentrate, on the acidified concentrate and on the bioleached batch residue (Figure $2 \mathrm{a}, \mathrm{b}$ and c). The concentrate's copper sulphides consisted of chalcocite $\left(\mathrm{Cu}_{2} \mathrm{~S}\right)$, covellite $(\mathrm{CuS})$, bornite $\left(\mathrm{Cu}_{5} \mathrm{FeS}_{4}\right)$ and chalcopyrite $\left(\mathrm{CuFeS}_{2}\right)$. After the ore acid pretreatment, proportions of bornite and chalcopyrite remained unchanged but the proportion of chalcocite decreased and that of covellite increased. This shows that acid pre-treatment leads to the transformation of chalcocite to covellite. After bioleaching, chalcocite and bornite were completely dissolved but some covellite ( $40 \%$ of total sulphides residue) and chalcopyrite ( $60 \%$ of total sulphides residue) remained. The chalcopyrite remaining represented $9 \%$ of the initial chalcopyrite. At the end of the five experiments, the Bioshale - BRGM consortium was codominated by Acidithiobacillus (At.) caldus (40 $\pm 2 \%$ ) and Leptospirillum (L.) ferriphilum ( $34 \pm 2 \%$ ). The species Sulfobacillus (Sb.) benefaciens BRGM2 and Sb. thermosulfidooxidans were detected at lower ratios (13 \pm 3 and $12 \pm 3 \%$ respectively). These results were highly reproducible which supports the fact that PCR-SSCP is very suitable to compare bacterial community structure. 


\subsection{Continuous bioleaching test}

The continuous bioleaching experiment was conducted with a different sample of copper concentrate. However, the chemical and mineralogical sulphide analyses showed that the two samples had almost the same characteristics. For the most important components $(\mathrm{Ag}$, inorganic and organic $\mathrm{C}, \mathrm{Cu}, \mathrm{Fe}$, sulphur as sulphide and $\mathrm{S}$ (total)), less than $10 \%$ deviation was noticed between the two samples. Concerning the mineralogical analysis, the second sample of concentrate contained more bornite $(+12.2 \%)$ and less covellite $(-6.7 \%)$ (Figure 2 a and $d)$. The grade of chalcopyrite, the mineral that will be the most studied in this work, was almost identical in both samples.

During the continuous bioleaching at $10 \%$ solids, the copper dissolution rate in the first reactor of the unit was estimated to be $147 \mathrm{mg} \mathrm{L}^{-1} \mathrm{~h}^{-1}, 42 \%$ less than in the batch culture. This shows that there is potential for improvement in the process performances. Residence time could be significantly reduced, bacteria being able to dissolve copper more quickly. The amount of copper solubilised from mass balance calculations was $77 \%$ after 3.3 days residence time, $85 \%$ after 4.9 days and $91 \%$ after 6.5 days. The final recovery in continuous mode appeared inferior to the one reached in batch cultures (between 95 and 97\%).

Some mineralogical studies of copper sulphides were conducted on the residue of the first and third tanks of the unit and compared to the mineralogical composition of the initial concentrate (Figure $2 \mathrm{~d}$, e and f). After 3.3 days of bioleaching (R1), all the chalcocite and almost all the bornite were dissolved; nevertheless, a major part of the initial chalcopyrite was still present and some covellite seemed to be produced. The remaining chalcopyrite was not solubilised in the second and third tanks. The final residue of the process contained traces of covellite ( $4 \%$ of the total sulphide's residue), and a significant amount of chalcopyrite ( $96 \%$ of the total sulphide's residue). This amount of chalcopyrite represented $44 \%$ of the concentrate's initial chalcopyrite. This is far more important than the chalcopyrite remaining at the end of the batch tests $(9 \%)$.

When the first reactor of the unit (R1) was run in batch mode, just before the continuous operation, the bacterial consortium was dominated by At. caldus (49\%) and L. ferriphilum (31\%). Sb. thermosulfidooxidans (21\%) was also well represented (Figure 3). After 12 days of continuous feeding of this reactor with $10 \%$ solids, an increase of $L$. ferriphilum ratio was observed to the detriment of 
Sb. thermosulfidooxidans. A comparable distribution of the population was monitored in the second reactor of the unit (R2). Sb. benefaciens was not detected in this series of experiments.

\subsection{Supplementary batch test}

A supplementary batch test was conducted by connecting one extra $20 \mathrm{~L}$ tank after the third reactor. Once full, it was run in batch mode. This was a means to extend the residence time of the pulp and to check if there was an effect on copper recovery.

The copper dissolution obtained during the batch period in the extra tank lead to a significant increase in the copper concentration, from $14.5 \mathrm{~g} \mathrm{~L}^{-1}$ to $17.6 \mathrm{~g} \mathrm{~L}^{-1}$. The copper contents of the residue was also impacted: a decrease from $2.1 \%$ to $1.1 \%$ was noticed.

The mineralogical analysis showed no significant modification of the residue's copper sulphide composition: chalcopyrite represented $92 \%$ of the total sulphide residue and covellite $8 \%$. However, the remaining chalcopyrite in the supplementary batch test was only $21 \%$ of the initial concentrate (vs. $44 \%$ after continuous bioleaching), showing a further dissolution of chalcopyrite during the batch period.

The molecular monitoring of the bacterial community structure showed that the same three microorganisms were again present: At. caldus (26\%), L. ferriphilum (37\%) and Sb. thermosulfidooxidans (37\%). The genus Sulfobacillus was, as in laboratory-scale batch tests and in the batch run to start the continuous operation, more represented than in the continuous mode.

\section{Discussion}

The aim of this study was to better understand the bioleaching of a multi-mineral concentrate originating from an organic-rich black-shale ore.

Before the batch bioleaching step, an acid pre-treatment was performed to dissolve most of the carbonates that may be detrimental to the start-up of bacterial growth. If the carbonate contents of an ore exceeds its acid producing potential, the organisms may not be able to maintain the acidic conditions required for their growth (Olson et al 2003). 
The concentrate was easily and efficiently bioleached in batch mode as more than $95 \%$ copper was recovered in 6.25 days. This result confirmed previous studies carried out on the same resource (Sadowski et al 2003; Szubert et al 2005). Three microorganisms found in the culture, At. caldus, L. ferriphilum, and Sb. thermosulfidooxidans were among the most common species found in stirred tank processes in mesophilic conditions (Olson et al 2003; Dopson and Lindström 2004; Shippers 2007). The reduced number of detected strains demonstrated once more the limited diversity of consortia that thrive in bioleaching processes (Okibe et al 2003). At. caldus and L. ferriphilum have already been found in the bioleaching consortium of a cobaltiferous pyrite in CSTR conditions (d'Hugues et al 2008). Sb. benefaciens (Johnson et al 2008) was the species of Sulfobacillus detected in these special conditions. The Bioshale-BRGM consortium is thus able to adapt to both cobaltiferous pyrite concentrate and copper black-shale concentrate. In fact, these microorganisms present all the functions required to efficiently perform the bioleaching reactions. The consortium combine iron and sulphur oxidizers and also autotrophic and mixotrophic microorganisms. At. caldus is an autotrophic sulphur oxidizer; it contributes indirectly to the oxidation of the mineral by inducing acidity and removing elemental sulphur. L. ferriphilum is an autotrophic iron-oxidizer resistant to high acidity and high ferric iron concentrations. Sulfobacillus spp. are mixotrophic sulphur and iron oxidizers that may use the organic material accumulating in the bioleached medium. They play a key role as it has been demonstrated that consortia with both autotrophic and heterotrophic microorganisms are more efficient than consortia containing only autotrophic bacteria (Battaglia Brunet et al 1998; Okibe and Johnson 2004). During bioleaching in continuous conditions, mineralogical analysis demonstrated that chalcocite and bornite were dissolved first. These minerals have the lowest rest potential of the sulphides that compose the concentrate; as a consequence, their dissolution is enhanced by the other sulphides (covellite and chalcopyrite). Some covellite was produced in a first step as it is an intermediary product of the dissolution of both chalcocite and chalcopyrite (Dixon 2000; Leahy et al 2007; Tshilombo et al 2002). Covellite was then almost completely dissolved in contrast to chalcopyrite which comprised the main part of the final residue. A schematic view of mineral dissolution mechanisms is proposed in Figure 4 (Gouin, 2008). 
The process was less efficient in terms of copper recovery in the continuous mode as compared to the batch mode. The main difference between these two modes was the reduced dissolution of chalcopyrite in continuous mode. $44 \%$ of the initial chalcopyrite remained at the end of the continuous pilot compared with $9 \%$ at the end of the batch experiment. This could explain the observed copper recovery difference ( $91 \%$ vs. $>95 \%)$. The supplementary batch test conducted in the follow-up of the continuous process confirmed this result: chalcopyrite remaining from the continuous process was further dissolved during the supplementary batch test period and led to an improvement of copper dissolution.

The discrepancy between batch and continuous processes is not easy to explain. However, this phenomenon seems to be related to a change in the bacterial community structure. Sulfobacillus was more abundant in batch conditions than in continuous conditions. Sulfobacillus did not represent more than $7 \%$ of the total population in the reactors of the continuous operation while it represented $21 \%$ in the batch culture used to start-up the unit and $37 \%$ in the supplementary batch reactor. As a consequence, in batch mode, sulphur oxidizers represented more than half of the bacterial population. A higher ratio of Sulfobacillus and more generally of sulphur oxidizers in the bioleaching population could be related to a better copper recovery, that is to say to a more efficient chalcopyrite dissolution. Particular conditions related to continuous mode may explain why Sulfobacillus is less represented in that case. It is well known that $\mathrm{CO}_{2}$ fixation by Sulfobacillus is less efficient than $\mathrm{CO}_{2}$ fixation by the other two organisms, L. ferriphilum and At. caldus (Okibe et al 2003; Rawlings 2005). Selection pressure being more important in continuous mode, Sulfobacillus was certainly disadvantaged by the limited availability of $\mathrm{CO}_{2}$. Another factor that may also have played a role is the ability to attach to the solid. Foucher et al. (2003) underlined that because of its reduced ability to attach to the solid, $S b$. thermosulfidooxidans seemed to be more affected than L. ferrooxidans and At. caldus by the culturing conditions. It was adversely affected by mechanical agitation. In the present study, it may be more impacted than other species by the continuous culture feeding. The main conclusion of this work is that a larger proportion of Sulfobacillus and a consequent dominance of sulphur oxidizers may favour chalcopyrite dissolution. There is a consensus saying that the reduction of chalcopyrite leaching kinetics is due to the formation of a hindering phase or 'passivation' film, which builds up 
on its surface. However, there is still a debate concerning the nature of this film. Four candidates are most often proposed: metal deficient sulphides, elemental sulphur, polysulphides and jarosites (Cordoba et al 2008; Klauber 2008; Rodriguez et al 2003). By oxidizing reduced inorganic sulphur compounds (RISC), sulphur oxidizers may be efficient in limiting surface hindering. It would be interesting to find continuous conditions more favourable to Sulfobacillus growth to maintain a high activity of RISC oxidation and so improving copper recovery.

\section{Acknowledgements}

This work was carried out in the frame of Bioshale (European project contract NMP2-CT-2004505710). The authors acknowledge the financial support given to this project by the European Commission under the Sixth Framework Programme for Research and Development. This paper is published with the permission of BRGM as scientific contribution No. 06792.

The authors would also like to thank KGHM Polska Miedź S.A. and KGHM Cuprum who provided the samples of the organic-rich polymetallic concentrate and Laurence Poirier (BRGM) and Antoine De Las Heras (BRGM) for their technical support.

\section{References}

Arrascue MEL, van Niekerk J (2006) Biooxidation of arsenopyrite concentrate using BIOX® process: Industrial experience in Tamboraque, Peru. Hydrometallurgy 83:90-96 Battaglia F, Morin D, Ollivier P 1(994) Dissolution of cobaltiferrous pyrite by Thiobacillus ferrooxidans and Thiobacillus thiooxidans - factors influencing bacterial leaching efficiency. J Biotechnol 32:11-16 Battaglia-Brunet F, d'Hugues P, Cabral T, Cezac P, Garcia JL, Morin D (1998) The mutual effect of mixed thiobacilli and leptospirilli populations on pyrite bioleaching. Miner Eng 11:195-205 Brierley C (2001) Bacterial succession in bioheap leaching. Hydrometallurgy 59:249-255 Brierley JA, Brierley CL (2001) Present and future commercial applications of biohydrometallurgy. Hydrometallurgy 59:233-239

Cancho L. Blázquez ML, Ballester A, González F, Muñoz JA (2007) Bioleaching of a chalcopyrite concentrate with moderate thermophilic microorganisms in a continuous reactor system.

Hydrometallurgy 87:100-111

Córdoba EM, Muñoz JA, Blázquez ML, González F, Ballester A (2008) Leaching of chalcopyrite with ferric ion. Part I: General aspects. Hydrometallurgy 93:81-87

d'Hugues P, Cezac P, Cabral T, Battaglia F, Truong-Meyer XM, Morin D (1997) Bioleaching of a cobaltiferous pyrite: a continuous laboratory-scale study at high solids concentration. Miner Eng 10:507-527 
d'Hugues P, Norris PR, Hallberg KB, Sánchez F, Langwaldt J, Grotowski A, Chmielewski T, Groudev S, Bioshale consortium (2008a) Bioshale FP6 European project: exploiting black shale ores using biotechnologies? Miner Eng 21:111-120

d'Hugues P, Joulian C, Spolaore P, Michel C, Garrido F, Morin D (2008b) Continuous bioleaching of a cobaltiferous pyrite in stirred reactors: population dynamics and EPS production vs. bioleaching performances. Hydrometallurgy 94:34-41

Demergasso CS, Galleguillos PA, Escudero LV, Zepeda VJ, Castillo D, Casamayor EO (2005) Molecular characterization of microbial populations in a low-grade copper ore bioleaching test heap. Hydrometallurgy 80:241-253

Dixon DG (2000) Analysis of heat conservation during copper sulphide heap leaching.

Hydrometallurgy 58:27-41

Dopson M, Lindström EB (1999) Potential role of Thiobacillus caldus in arsenopyrite bioleaching. Appl Environ Microb 65:36-40

Foucher S, Battaglia-Brunet F, d'Hugues P, Clarens M, Godon JJ, Morin D (2003) Evolution of the bacterial population during the batch bioleaching of a cobaltiferous pyrite in a suspended-solids bubble column and comparison with a mechanically agitated reactor. Hydrometallurgy 71:5-12 Gericke M, Pinches A (1999) Bioleaching of copper sulphide concentrate using extreme thermophilic bacteria. Miner Eng 12:893-904

Gouin J (2008) Mode de genèse et valorisation des minerais de type black shales : cas du Kupferschiefer (Pologne) et des schistes noirs de Talvivaara (Finlande). PhD thesis, University of Orléans

Halinen AK, Rahunen N, Kaksonen AH, Puhakka A (2009) Heap bioleaching of a complex sulfide ore. Part I: Effect of $\mathrm{pH}$ on metal extraction and microbial composition in $\mathrm{pH}$ controlled columns. Hydrometallurgy 98:92-100

Helle S, Kelm U (2005) Experimental leaching of atacamite, chrysolla and malachite: relationship between copper retention and cation exchange capacity. Hydrometallurgy 78:180-186

Johnson DB, Hallberg KB (2007) Techniques for detecting and identifying acidophilic mineral oxidizing microorganisms. In: Rawlings DE, Johnson DB (ed) Biomining. Springer-Verlag, Berlin Heidelberg, pp 237-261

Johnson DB, Joulian C, d'Hugues P, Hallberg KB (2008) Sulfobacillus benefaciens sp. Nov., an acidophilic facultative anaerobic Firmicute isolated from mineral bioleaching operations.

Extremophiles 12:789-798

Klauber C (2008) A critical review of the surface chemistry of acidic ferric sulphate dissolution of chalcopyrite with regards to hindered dissolution. Int J Miner Process 86:1-17

Leahy MJ, Davidson MR, Schwarz MP (2007) A model for heap bioleaching of chalcocite with heat balance: Mesophiles and moderate thermophiles. Hydrometallurgy 85:24-41

López-Juárez A, Rivera-Santillán RE (2005) Bioleaching of a cananea copper concentrate in laboratory-scale continuous stirred reactors. In: Harrison STL et al. (ed) Proceedings of the 16th International Biohydrometallurgy Symposium, Cape Town, South Africa pp 283-289

Márquez M, Gaspar J, Bessler KE, Magela G. (2006) Process mineralogy of bacterial oxidized gold ore in São Bento Mine (Brasil). Hydrometallurgy 83:114-123 
Morin D, d'Hugues P (2007). Bioleaching of a cobalt-containing pyrite in stirred reactors: a case study from laboratory scale to industrial application. In: Rawlings DE, Johnson DB (ed)

Biomining. Springer-Verlag, Berlin Heidelberg, pp35-56

Okibe N, Gericke M, Hallberg KB, Johnson DB (2003) Enumeration and characterization of acidophilic microorganisms isolated from a pilot plant stirred-tank bioleaching operation. Appl

Environ Microbiol 69:1936-1943

Okibe N, Jonhson DB (2004) Bioleaching of pyrite by defined mixed populations of moderately thermophilic acidophiles in $\mathrm{pH}$-controlled bioreactors: significance of microbial interactions.

Biotechnol Bioeng 87:574-583

Olson GJ, Brierley JA, Brierley CL (2003) Bioleaching review part B: Progress in bioleaching: applications of microbial processes by the minerals industries. Appl Microbiol Biotechnol 63:249257

Pani CK, Swain S, Kar RN, Chaudhury GR, Sukla LB, Misra VN (2003) Bio-dissolution of zinc sulfide concentrate in 1601 4-stage continuous bioreactor. Miner Eng 16:1019-1021

Rawlings DE (2005) Characteristics and adaptability of iron- and sulfur-oxidizing microorganisms used for the recovery of metals from minerals and their concentrates. Microbial cell factories 4:13 Rodriguez, Y., Ballester, A., Blazquez, M.L., Gonzalez, F., Munoz, J.A. 2003. New information on the pyrite bioleaching mechanism at low and high temperature. Hydrometallurgy 71, 37-46 Sadowski Z, Jazdzyk E, Karas H (2003) Bioleaching of copper ore flotation concentrates. Miner Eng 16:51-53

Shippers A (2007) Microorganisms involved in bioleaching and nucleic acid-based molecular methods for their identification and quantification. In: Donati ER, Sand W (ed) Microbial processing of metal sulfides. Springer, Dordrecht, pp3-34

Spolaore P, Joulian C, Gouin J, Morin D, d'Hugues P (2009) Bioleaching of an organic-rich polymetallic concentrate using stirred-tank technology. Hydrometallurgy 99:137-143 Szubert A, Sadowski Z, Maliszewska I, Gros CP, Barbe JM, Guilard R, Polowczyk I, Jazdzyk (2005) Biotreatment of polish black shale ores. In: Harrison STL, Rawlings DE, Petersen J (ed) Proceedings of the 16th International Biohydrometallurgy Symposium, Cape Town, South Africa, pp227-236

Tshilombo AF, Petersen J, Dixon DG (2002) The influence of applied potentials and temperature on the electrochemical response of chalcopyrite during bacterial leaching. Miner Eng 15:809-813 Van Aswegen PC, Van Niekerk J, Olivier W (2007) The BIOX process for the treatment of refractory gold concentrates. In: Rawlings DE, Johnson DB (ed) Biomining. Springer-Verlag, Berlin Heidelberg, pp1-34

Wakeman K, Auvinen H, Johnson DB (2008) Microbiological and geochemical dynamics in simulated-heap leaching of a polymetallic sulfide ore. Biotechnol Bioeng 101:739-750 Watling HR (2006) The bioleaching of sulphide minerals with emphasis on copper sulphides - A review. Hydrometallurgy 84:81-108

Whittington BI, McDonald RG, Johnson JA, Muir DM (2003a) Pressure acid leaching of aridregion nickel laterite ore. Part I: effect of water quality. Hydrometallurgy 70:31-46 
Whittington BI, Johnson JA, Quan LP, McDonald RG, Muir DM (2003b) Pressure acid leaching of arid-region nickel laterite ore. Part II: effect of ore type. Hydrometallurgy 70:47-62

Zhang R, Wei M, Ji H, Chen X, Qiu G, Zhou H (2009) Application of real-time PCR to monitor population dynamics of defined mixed cultures of moderate thermophiles involved in bioleaching of chalcopyrite. Appl Microbiol Biotechnol 81:1161-1168

\section{Figure legends}

Fig 1 Batch bioleaching in stirred reactors with the Bioshale-BRGM consortium. Copper concentration vs. time (mean and standard deviation for five identical tests)

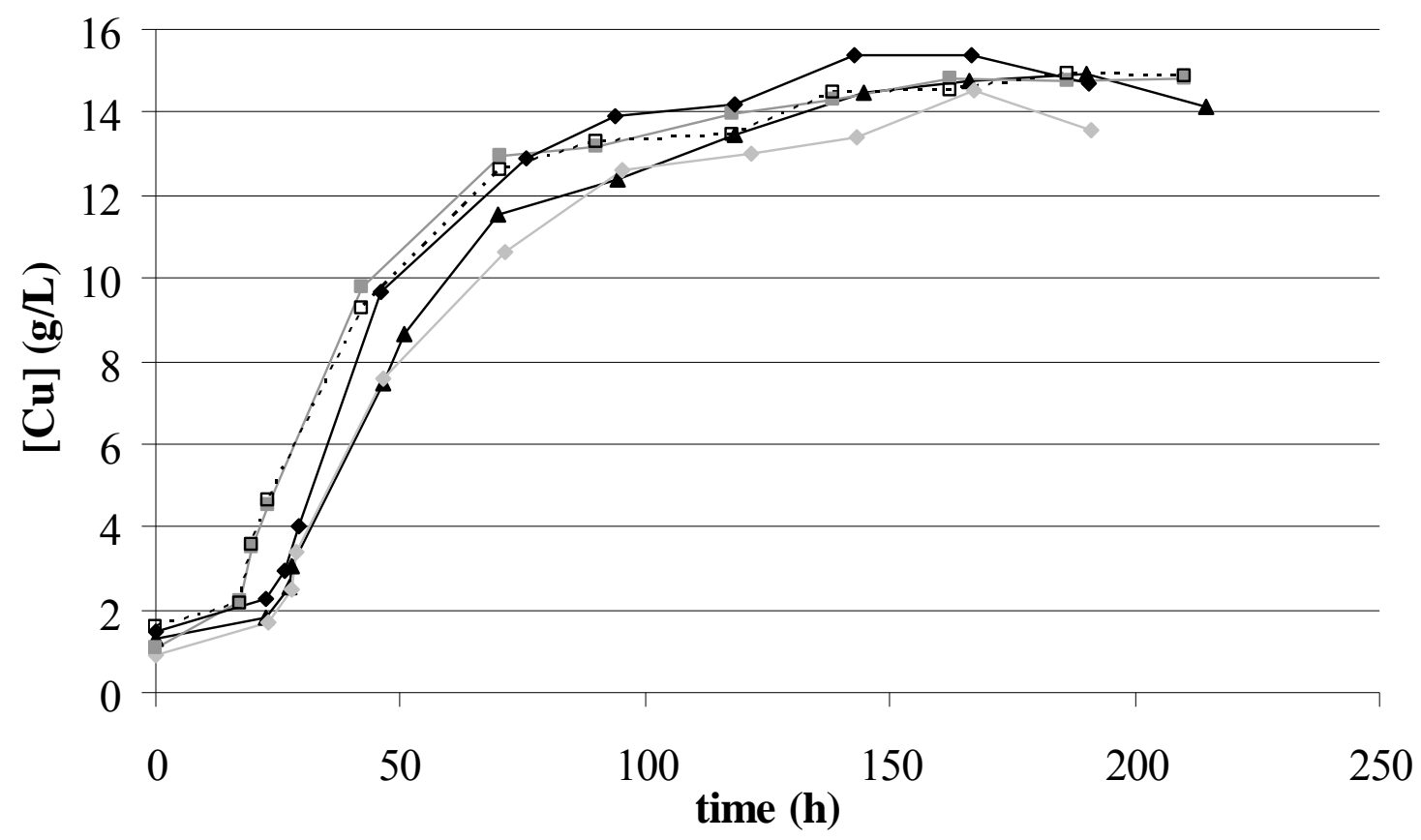


Fig 2 Comparison of the copper sulphides composition of (a) Lubin concentrate sample 1 (b) sample 1 after acid pre-treatment (c) sample 1 batch bioleached residue (d) Lubin concentrate sample 2 (e) sample 2 bioleached residue from R1 of the continuous operation and (f) sample 2 bioleached residue from R3 of the continuous operation

a
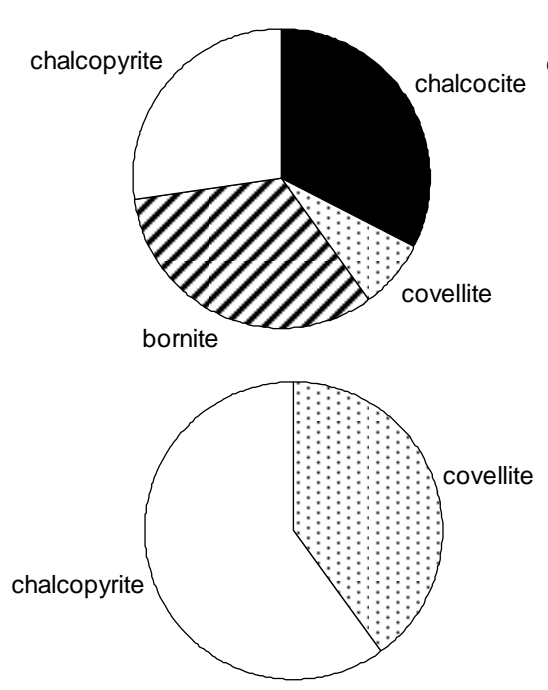

$\mathrm{b}$

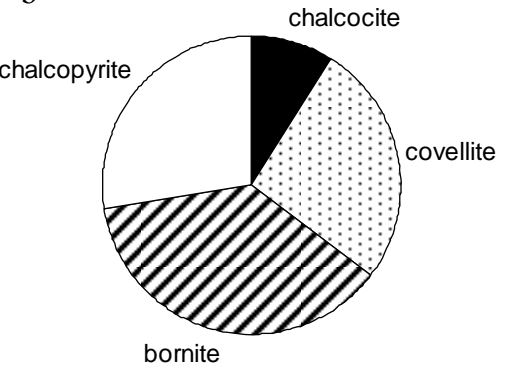

c
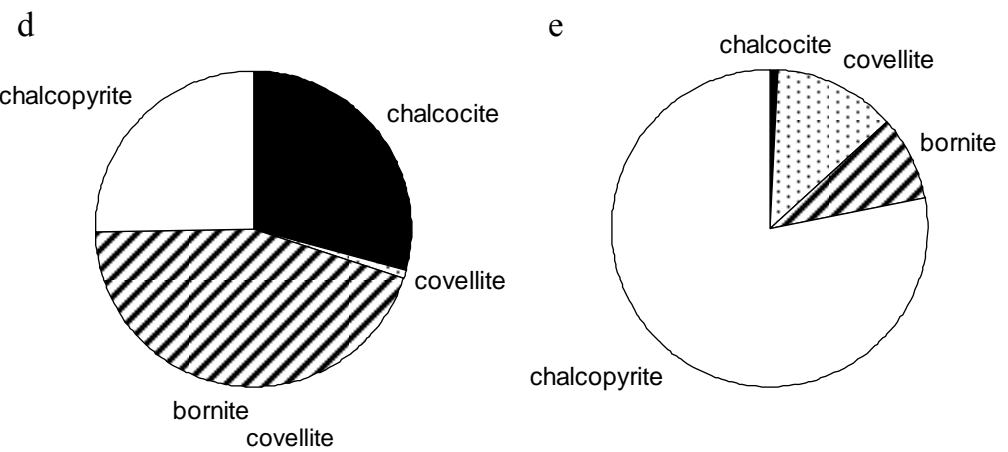

f

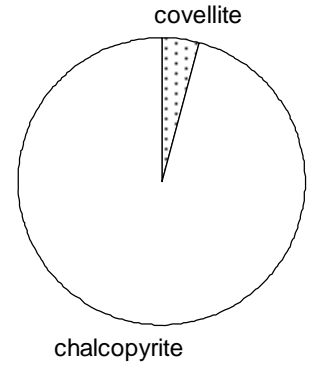


Fig 3 Molecular monitoring of the bacterial community structure in the continuous pilot unit: batch test before continuous feed (R1), after 12 days in continuous mode (R1 and R2) and in the supplementary batch test (R4). Black bars: Sb. thermosulfidooxidans, white bars: L. ferriphilum BRGM1 and grey bars: At. caldus (semi-quantitative results)

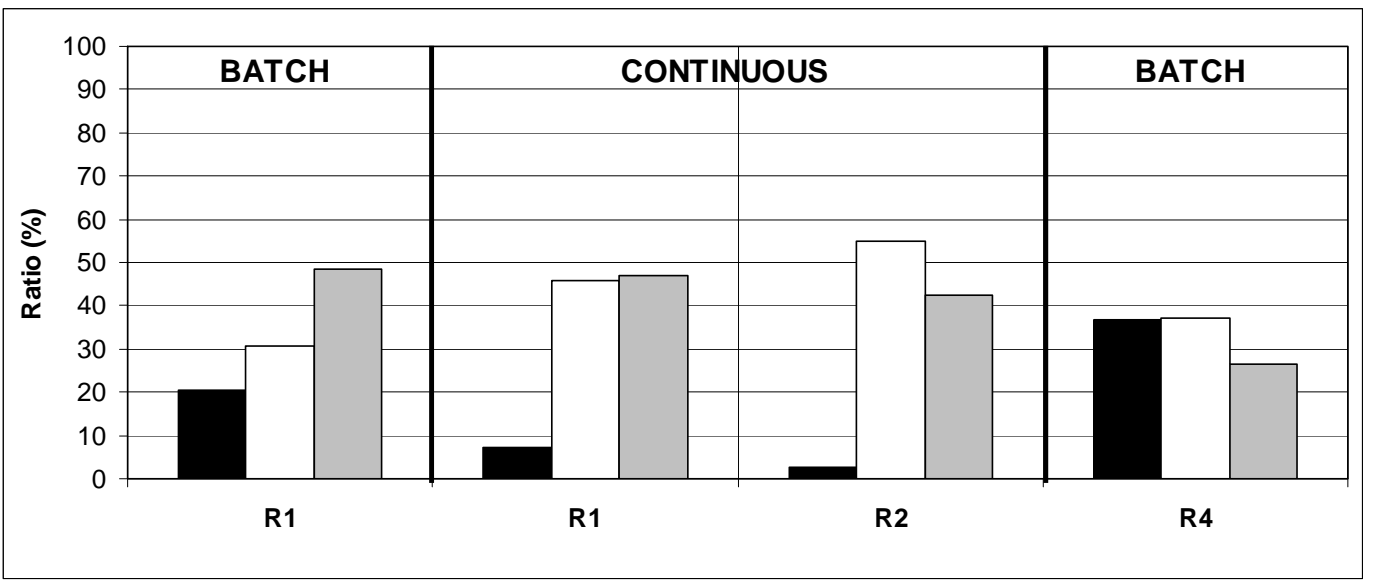

Fig 4 Schematic view of the sulphide dissolution mechanism during Lubin concentrate bioleaching in the continuous mode. The nature of the arrow describes the quantity of sulphides transferred from the feed (Lubin concentrate) to the reactors (R1 and R3); - - $\rightarrow$ indicates a very limited quantity and indicates the quasi totality of the sulphides. Covellite (I) is the primary covellite; covellite(II) is the secondary covellite originating from partial dissolution of chalcocite and chalcopyrite

$\begin{array}{lc}\text { Lubin } & \text { bornite } \\ \text { concentrate } & \\ \text { R1 } & \text { bornite }\end{array}$

R3

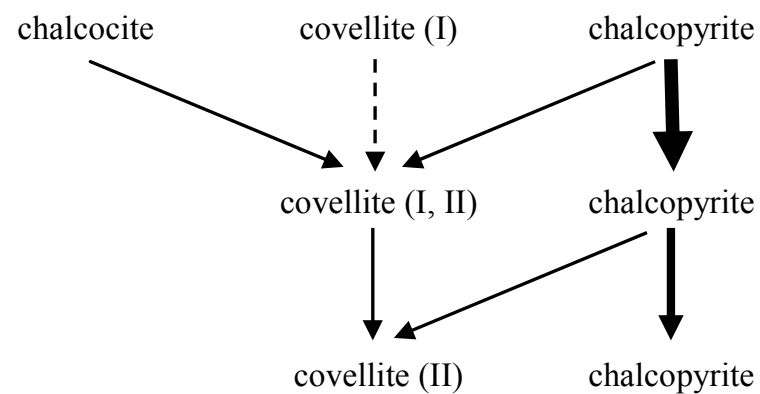

